\title{
Good Zakat Governance; The Mustahiq-Muzakki Transformation Report Model
}

\author{
Muhammad Hatta Fahamsyah ${ }^{1}$, Muhamad Wahyudi ${ }^{2}$ \\ hatta@pelita@bangsa.ac.id¹,wahyudi_arridho@untidar.ac.id \\ Universitas Pelita Bangsa ${ }^{1}$, Universitas Tidar $^{2}$
}

\begin{abstract}
Poverty is a matter of human life. Islam puts poverty into the number two problem after the faith. Islam as a perfect religion has provided a solution to the problem of poverty through the zakat mechanism. Good zakat management (Good Zakat Governance / GZG) is a demand for all Zakat Management Institution (ZMI). Full Disclosure in the ZMI financial statements is a must in order to attract the trust of the muzakki and is part of the GZG practices that must be carried out by ZMI. This paper aims to propose a reporting model for transformation of mustahik into muzakki to complement the financial statements presented by the ZMI. This report model is a form of transparency in good zakat management (Good Zakat Governance).
\end{abstract}

Keywords: zakat, transformation, Good Zakat Governance

\section{Pendahuluan}

Isu zakat masih menjadi topik yang terus dikaji. Salah satunya berkaitan akuntabilitas dan transparansi [1], [2], [3], [4], [5], yang menyimpulkan akuntabilitas Organisasi Pengelola Zakat (OPZ) terhadap PSAK belum sesuai. Akuntabilitas pengelolaan zakat mempunyai hubungan posisitf terhadap tingkat pengumpulan dana ZIS [6]. Studi yang dilakukan oleh [7] tentang praktik pelaporan zakat di Malaysia, pengungkapan laporan pengelolaan zakat menjadi faktor yang mempengaruhi ketaatan membayar zakat.

Berdasarkan data dan fakta-fakta tersebut pertanyaan yang menarik untuk dijawab adalah bagaimana OPZ mampu menarik kepercayaan muzakki agar dapat mengoptimalkan pengumpulan dana ZIS [8], [9]. Dan bagaimana seharusnya OPZ menyajikan laporan keuangan yang memenuhi unsur akuntabilitas bagi stakeholders. Melalui paper ini akan dikaji bagaimana konsepsi islam tentang zakat dalam mengentaskan kemiskinan dan bagaimana seharusnya OPZ sebagai lembaga yang diberi wewenang mengelola ZIS sebagai sarana menjadikan seorang mustahik bertransformasi menjadi muzakki, serta bagaimana model pelaporan transformasi mustahik menjadi muzakki.

\section{Studi Literatur}

\section{Good Governance OPZ dan Transformasi Mustahik}

Konsep good governance pada awalnya dimaknai sebagai sistem tata kelola dalam mengendalikan jalannya sebuah perusahaan. Tata kelola merupakan serangkaian mekanisme, proses yang saling berhuhungan dalam suatu organisasi yang dikontrol dan di jalankan secara efektif [10]. Dalam tataran pratek, good governance dimaknai sebagai suatu mekanisme perusahaan berusaha memenuhi tanggungjawabnya kepada stakeholder [11]. Terdapat delapan 
sebagaimana UNESCAP yaitu partisipatif, berorientasi pada consensus, akuntabel, transparan, responsive, efektif, dan efisien, adil dan inklusif serta taat aturan [12]. Sementara Komite Nasional Kebijkan Corporate Governance, terdapat lima prinsip yakni transparansi, akuntabilitas, responsibilitas, independensi dan fainess [11]. Sebagai organisasi nirlaba yang mengelola dana masyarakat maka OPZ wajib melaksanakan prinsip good governance, meliputi akuntabilitas dan transparansi. [12]

Meskipun OPZ merupakan lembaga nir laba. Namun dalam praktiknya OPZ banyak berhubungan dengan berbagai pihak yang berkepentingan terutama adalah para pembayar zakat (muzakki). Oleh sebab itu dalam hubungan ini akan timbul konsekuensi logis OPZ mempertanggunjawabkan zakat, infak, sedekah dan dana-dana sosial lainnya kepada masyarakat. bentuk pertanggungjawaban ini disampaikan melalui laporan keuangan yang diterbitkan secara berkala dan publikasikan kepada masyarakat [13]. Akuntabilitas [14]. Pertanggungjawaban ini tidak hanya sebatas pada informasi berapa jumlah dana yang diterima dan disalurkan kepada siapa, akan tetapi lebih luas daripada itu adalah pertanggungjawaban bagaimana laporan pencapaian OPZ dalam menjalankan fungsi dan perannya sebagai amil zakat dalam mengentaskan kemiskinan.

Transformasi mustahiq menjadi muzakki sebagaimana gambar 1 berikut.

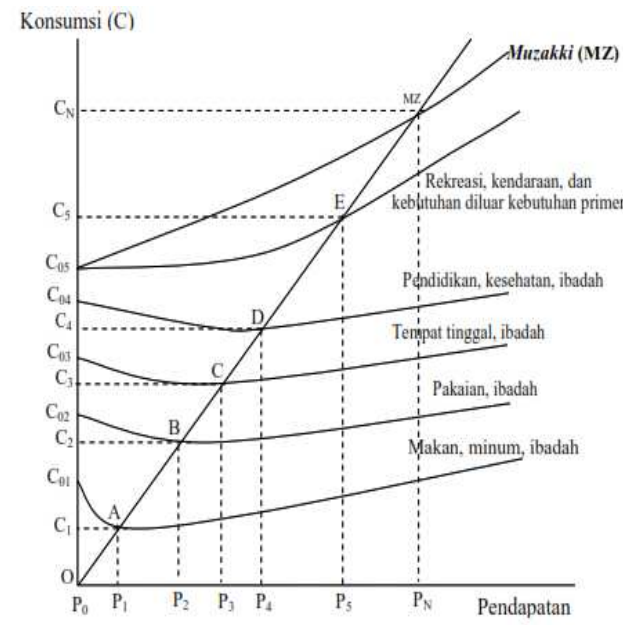

Gambar 1 Tranformasi fakir miskin menjadi muzakki

Sumber: Nafik HR, (2012)

\section{Pembahasan}

\section{Laporan Transformasi Mustahik}

Laporan transformasi zakat merupakan model laporan yang dibangun dari kerangka pemikiran tentang fungsi zakat sebagai media transformasi dari seorang mustahik menjadi muzakki. Dalam laporan ini akan disajikan berapa jumlah dana zakat yang disalurkan yang dirinci sesuai kategorinya $Z_{0}-Z_{4}$ dan berapa jumlah mustahik yang menerima.

Laporan ini disajikan dalam satu format selama lima tahun berturut-turut. Kurun waktu lima tahun merupakan kurun waktu yang dianggap cukup bagi seorang mustahik bertransformasi menjadi muzakki. Disamping itu kurun waktu lima tahun menjadi dasar bagi OPZ untuk merancang suatu program pengentasan kemiskinan melalui zakat secara efektif 
dan terukur. Laporan transformasi mustahik ini menjadi sangat penting mengingat kewajiban OPZ menyampaikan laporan keuangan saat ini belum menyajikan informasi secara detail perihal berapa jumlah mustahik yang telah berubah menjadi muzakki. Informasi yang tersaji selama ini hanya diketahui berapa jumlah dana yang terima dan jumlah yang disalurkan. Perubahan jumlah penerima zakat tidak diketahui secara jelas apakah orang yang sama atau orang yang berbeda. Jika merupakan orang yang sama bagaimana informasi keadaan riillnya tidak diketahui. Jika orang yang mnerima telah berganti dengan orang lain lantas bagaimana dengan orang yang tidak menerima lagi. Melalui laporan transforamasi mustahik ini informasi seputar mustahik baik jumlah dan kondisi masing-masing mustahik dapat diketahui secara berkala. Dalam konteks pengukuran kinerja laporan transformasi ini dapat digunakan sebagai cara untuk mengukur efektifitas kinerja lembaga OPZ. Melalui laporan ini OPZ dapat mengetahui keberhasilan program pengelolaan zakat, serta dapat menjadi bahan untuk melakukan evaluasi dan perbaikan yang diperlukan. Berikut disajikan simulasi laporan transformasi mustahik menjadi muzakki dalam tabel. 1 di bawah ini:

Tabel. 1 Format Laporan Transformasi Mustahiq

\begin{tabular}{|c|c|c|c|c|c|}
\hline Keterangan & $\begin{array}{c}\text { Jumlah } \\
\text { Penerima } \\
\text { zakat }\end{array}$ & $\begin{array}{l}\text { Jumlah } \\
\text { Pend. } \\
\text { Mustahik } \\
\text { (Rp) }\end{array}$ & $\begin{array}{c}\text { Jumlah } \\
\text { Kebutuhan } \\
\text { Mustahik } \\
(\mathrm{Rp}) \\
\end{array}$ & $\begin{array}{c}\text { Jumlah Zakat } \\
\text { untuk } \\
\text { konsumsi } \\
(\mathrm{Rp}) \\
\end{array}$ & $\begin{array}{c}\text { Jumlah Zakat } \\
\text { untuk } \\
\text { meningkatkan } \\
\text { pendapatan (Rp) }\end{array}$ \\
\hline $\begin{array}{l}\text { Thn Ke-1 Kategori } \\
\left(\mathrm{P}_{0}, \mathrm{C}_{1}, \mathrm{Z}_{1}, \mathrm{Z}_{\mathrm{p}}\right)\end{array}$ & 10 & 0 & 50 & 500 & 500 \\
\hline $\begin{array}{l}\text { Thn Ke-2 Kategori } \\
\left(\mathrm{P}_{1}, \mathrm{C}_{2}, \mathrm{Z}_{2}, \mathrm{Z}_{\mathrm{p}}\right)\end{array}$ & 10 & 50 & 100 & 500 & 300 \\
\hline $\begin{array}{l}\text { Thn Ke-3 Kategori } \\
\left(\mathrm{P}_{2}, \mathrm{C}_{3}, \mathrm{Z}_{2}, \mathrm{Z}_{\mathrm{p}}\right)\end{array}$ & 10 & 75 & 150 & 750 & 200 \\
\hline $\begin{array}{l}\text { Thn Ke-4 Kategori } \\
\left(\mathrm{P}_{3}, \mathrm{C}_{4}, \mathrm{Z}_{3}, \mathrm{Z}_{\mathrm{p}}\right)\end{array}$ & 10 & 125 & 200 & 250 & 100 \\
\hline $\begin{array}{l}\text { Thn Ke-5 Kategori } \\
\left(\mathrm{P}_{4}, \mathrm{C}_{4}, \mathrm{Z}_{0}, \mathrm{Z}_{\mathrm{p}}\right)\end{array}$ & 10 & 200 & 200 & 0 & 0 \\
\hline
\end{tabular}

Keterangan:

$\mathrm{P}_{0-4}$ : Pendapatan

$\mathrm{C}_{1-4}$ : Konsumsi

$\mathrm{Z}_{1-4}$ : Alms Consumption

$\mathrm{Z}_{\mathrm{p}} \quad$ : Zakat Produktif
Asumsi:

1. Jumlah kebutuhan normal $\mathrm{C}_{1}=50, \mathrm{C}_{2}=100, \mathrm{C}_{3}=150, \mathrm{C}_{4}=$ $200, \mathrm{C}_{5}=200$

2. Jumlah pendapatan $\mathrm{P}_{1}=50, \mathrm{P}_{2}=75, \mathrm{P}_{3}=125, \mathrm{P}_{4}=200$

Laporan ini disajikan secara kontinyu selama lima tahun untuk mengetahui perkembangan proses musahik menjadi muzakki. Sehingga dengan kata lain periode transformasi mustahik ke muzakki adalah lima tahunan. Namun demikian, meskipun periodenya lima tahunan OPZ tetap dapat membuka periode lima tahun pada setiap tahunnya sesuai dengan kemampuan dari OPZ masing-masing. Tabel di atas merupakan periode lima tahun pertama tahun $20 \mathrm{X} 1-20 \mathrm{X} 5$, pada tahun berikutnya OPZ bisa membuka periode lima thaun ke dua yaitu tahun $20 \times 2-20 X 6$ dan seterusnya.

Dalam laporan di atas terdapat beberapa asumsi yaitu; pertama diasumsikan bahwa selama lima tahun OPZ menyalurkan zakat kepada mustahik sebanyak 10 orang secara konstan. Mustahik dalam simulasi di atas adalah yang masuk kategori fakir. Yakni orang yang tidak mempunyai pendapatann sama sekali untuk memenuhi kebutuhannya. Asumsi kedua 
besaran kebutuhan normal mustahik adalah $C_{1}=50, C_{2}=100, C_{3}=150, C_{4}=200, C_{5}=200$. Asumsi ketiga pendapatan mustahik adalah $\mathrm{P}_{1}=50, \mathrm{P}_{2}=75, \mathrm{P}_{3}=125, \mathrm{P}_{4}=200$.

Berdasarkan simulasi laporan di atas diketahui bahwa pada tahun pertama OPZ menyalurkan zakat kepada 10 orang fakir. Fakir miskin merupakan orang yang sama sekali tidak memiliki pendapatan oleh sebab itu OPZ menanggung seluruh kebutuhan mustahik sebesar $C_{1}$ yakni Rp. 500 ditambah dengan zakat produktif sebesar Rp. 500 untuk membantu mustahik mendapatkan tambahan penghasilan menjadi $\mathrm{P}_{1}$.

Pada tahun ke dua jumlah zakat yang disalurkan untuk konsumsi sebesar Rp. 500 sama dengan tahun ke pertama mengingat jumlah konsumsi bertambah menjadi $\mathrm{C}_{2}$ sementara mustahik hanya mampu menghasilkan pendapatan sebesar $P_{1}$. Dengan jumlah pendapatan sebesar $\mathrm{P}_{1}$ belum mampu mencukupi kebutuhan konsumsinya sebesar $\mathrm{C}_{2}$. Sehingga masih mendapatkan zakat konsumsi sebesar $Z_{2}$ dan disisi lain OPZ masih memberikan zakat produktif sebesar Rp. 300 untuk membantu mustahik menambah pendapatan pada tahun ke tiga menjadi $\mathrm{P}_{2}$

Pada tahun ke tiga OPZ menyalurkan zakat sebesar Rp. 250 lebih sedikit dibandingkan tahun sebelumnya. Berkurangnya zakat untuk konsumsi yang disalurkan disebabkan mustahik behasil meningkatkan pendapatannya menjadi $\mathrm{P}_{2}$ sehingga dapat membantu memenhui kebutuhannya sebesar $\mathrm{C}_{3}$. Akan tetapai OPZ masih menyalurkan zakat produktif kepada mustahik sebesar Rp. 200 agar mustahik dapat meningkatkan penghasilannya menjadi $\mathrm{P}_{3}$.

Pada tahun ke empat OPZ menyalurkan zakat konsumsi sebesar Rp. 250 atau $\mathrm{C}_{4}$. Pada tahun ke 4 ini mustahik masih menerima zakat konsumsi meskipun telah mampu memperoleh pendapatan sebesar $\mathrm{P}_{3}$, akan tetapi belum cukup untuk memenuhi seluruh kebutuhanya sebesar $\mathrm{C}_{4}$. Pada tahun ke empat ini mustahik akan menerima zakat produktif sebesar Rp. 100 untuk membantu meningkatkan pendapatan menjadi sebesar $\mathrm{P}_{4}$. Memasuki tahun ke lima mustahik tidak akan menerima baik zakat konsumsi maupun zakat produktif karena diasumsikan mustahik telah mempunyai kemampuan menghasilkan pendapatan sebesar $\mathrm{P}_{4}$, jumlahnya sama dengan diperlukan untuk memenuhi kebutuhan konsumsi sebesar $\mathrm{C}_{4}$, maka dengan demikian mustahik tidak berhak lagi menerima zakat. Dengan kata lain ia telah berubah setatusnya tidak lagi masuk kategori fakir dan miskin, namun telah bertransformasi masi menjadi seorang calon muzakki (wajin zakat).

Model laporan transformasi ini sangat relevan dengan praktik penyalura zakat yang banyak dilakukan oleh OPZ, baik BAZNAS maupun OPZ yang dikelola lembaga swadaya masyarakat. Melalui laporan akan dapat diketahui efektivitas penyaluran zakat yang dilakukan oleh OPZ. Laporan ini akan dapat meningkatkan kepercayaan sekalian penilaian muzakki atas kinerja OPZ terutama dalam hal transparansi pelaporan keuangan. Model laporan ini bersifat sukarela dan merupakan laporan yang bersifat tambahan atas laporan yang mesti disajikan oleh OPZ setiap tahun sekali.

\section{Kesimpulan}

Praktik good governance pada lembaga pengelola zakat merupakan tuntutan yang wajib dipenuhi. Salah satunya adalah dalam hal penyajian laporan keuangan. Model laporan transformasi mustahik merupakan laporan yang memberikan informasi yang rinci tentang pengaruh pemberian zakat kepada kehidupan seorang mustahik. Melalui laporan transformasi ini akan diketahui bagaimana proses seorang mustahik bertransformasi menjadi muzakki. Selain itu bagaiman efektivitas program penyaluran zakat yang dilaksanakan oleh lembaga pengelola zakat juga dapat diketahui dengan menggunakan informasi yang tesaji dalam laporan ini. Penyajian laporan transformasi mustahik merupakan bagian dari pelaksanaan 
prinsip transparansi sekaligus prinsip akuntabilitas dalam pratik good governance. Oleh sebab itu adalah suatu keputusan yang baik bagi organisasi pengelola zakat untuk menyajikan model laporan ini, sebagai tambahan dalam laporan keuangan yang disampaikan kepada stakeholder. Informasi tambahan ini diharapakan dapat meningkatkan kepercayaan muzakki terhadap lembaga pengelola zakat shingga dapat memaksimalkan potensi penerimaan zakat, infak dan sedekah.

\section{References}

[1] N. A. Wahab, A. Rahim, and A. Rahman, "A framework to analyse the efficiency and governance of zakat institutions," J. Islam. Account. adn Bus. Resecarh, vol. 2, no. 1, pp. 43-62, 2011.

[2] D. Hafidhuddin, Anda Bertanya Tentang Zakat, Infak, dan Sedekah Kami Menjawab. Jakarta: Gema Insani, 2018.

[3] Y. Puspitasari and H. Habiburrochman., "Penerapan PSAK No. 109 Atas Pengungkapan Wajib Dan Sukarela," J. Akunt. Multiparadigma, vol. 4, no. 3, pp. 479-494, 2013.

[4] Nikmatuniayah and M. Marliyati, "Akuntabilitas Laporan Keuangan Lembaga Amil Zakat di Kota Semarang,” Mimb. J. Sos. dan Pembang., vol. 31, no. 2, pp. 485-494, 2015.

[5] H. . T. Hasibuan, "Statement of Financial Accounting Standard (PSAK) No. 109 and Its Implementation in Several Zakat Management Organizations in Malang, East Java," Shirkah J. Econ. Bus., vol. 1, no. 3, pp. 339-354, 2016.

[6] D. F. Septiarini, "Pengaruh Transparansi dan Akuntabilitas Terhadap Pengumpulan Dana Zakat, Infaq dan Shodaqoh pada LAZ di Surabaya," AKRUAL J. Akunt., vol. 2, no. 2, p. 172, 2011.

[7] N. Samargandi, S. M. Tajularifin, and E. K. Ghani, "Can disclosure practices and stakeholder management influence zakat payers ' trust? A Malaysian evidence," BEH Bus. Econ. Horizons, vol. 4, no. 4, pp. 882-893, 2018.

[8] N. Samargandi, S. M. Tajularifin, and E. K. Ghani, "Can disclosure practices and stakeholder management influence zakat payers ' trust? A Malaysian evidence,” no. 2002, 2018.

[9] H. S. Kuncaraningsih and M. R. Ridla, "Good Corporate Governance di Badan AMIL Zakat Nasional,” J. MD, no. Januari-Juni, pp. 97-115, 2015.

[10] D. Kusumastuti, “Apakah Penerapan Tata Kelola yang Baik Mampu Mendorong Kinerja Pengelolaan Zakat: Telaah Sistematis Hasil Studi-studi Empiris di Indonesia," Mabsya J. Manaj. Bisnis Syariah, vol. I, no. 1, pp. 79-98, 2018.

[11] P. Lestari, U. Pratiwi, and P. Ulfah, "Identifikasi Faktor Organisasional Dalam Pengembangan EGovernance Pada Organisasi Pengelola Zakat Di Kabupaten Banyumas,” MIMBAR, J. Sos. dan Pembang., vol. 31, no. 1, pp. 221-232, 2015.

[12] N. W. I. Rahayu, "Lembaga Amil Zakat, Politik Lokal, Dan Good Governance Di Jember," KARSA J. Sos. dan Budaya Keislam., vol. 22, no. 2, p. 207, 2015.

[13] Y. Puspitasari and Habiburrochman, "Penerapan PSAK No . 109 atas Pengungkapan Wajib dan Sukarela," J. Multi Paragidma, vol. 330-507, no. 3, pp. 20-42, 2018.

[14] I. Fitrah, "Prinsip-prinsip Good Governance pad Pengelolaan Zakat dalam Perspektif Qardhawi: Studi pada Baitul Mal Kabupaten Aceh Tengah,” Jurisdictie, vol. 8, no. 1, pp. 21-32, 2017.

[15] M. Nafik H.R, “Tanggungjawab Lembaga Ekonomi Islam Muzakki,” eL-Qist, vol. 02, no. 02, pp. $257-278,2012$. 